\title{
Evaluating the Effectiveness of the Momentum Strategy for Responsible Investment in the Russian Stock Market
}

\author{
Danila Ovechkin, Liudmila Reshetnikova, and Natalia Boldyreva* \\ University of Tyumen, 625003 Tyumen, Russia
}

\begin{abstract}
In modern conditions, the integration of ESG-criteria into investment decisions of asset managers is considered as a key factor in sustainable economic development. We examine the effectiveness of the Momentum-ESG strategy based on the Responsibility and Openness Index in comparison with the Momentum strategy, which is based on the Moscow Exchange Broad Market Index, since December 2011 to December 2020. We propose an algorithm for integrating ESG criteria into momentum strategy. We select "winners" and "losers" stocks based on their monthly return. The Momentum-ESG strategy has a high Sharpe ratio for a time horizon of 12 months, the Momentum strategy - for a time horizon of 6 months. The testing of the Momentum-ESG strategy shows its greater efficiency in terms of the Sharpe ratio compared to the Momentum strategy, which does not take into account the ESG-factors, in the investing period.
\end{abstract}

\section{Introduction}

The modern world trend in the economic sphere is associated with the creation of conditions for achieving long-term sustainable efficiency of the country's economy. The global community links sustainable development including responsible investment. It is based on ESG-factors: environmental, social, corporate governance. This involves integrating ESG criteria into the investment business.

Researchers have noted an increase the importance of ESG-ratings for retail and institutional investors (pension, investment funds, insurance companies) since the zero years [1,2]. Integration of the ESG into the field of asset management leads to an assessment of their effectiveness in terms of broader impact on society. However, this does not negate the consideration of risk and investment returns factors. The sustainable development goals assume that investment in companies can only be profitable in the long term if society develops in an equitable and sustainable manner. The modern challenge is the combination of high efficiency of investment strategies with a responsible investment.

Investment strategy is one of the key factors of asset managers effectiveness. Various investment strategies are known in the investment theory and practice. Momentum

* Corresponding author: naboldyreva@yandex.ru 
strategies have attracted close attention of foreign and domestic researchers in the early $90 \mathrm{~s}$ 20 -ou and in the 10 s of the 21 st centuries accordingly. Research shows their performance for different asset classes in developed and emerging financial markets.

Russian companies are not required to disclose information about ESG, therefore empirical researches about the integration of ESG into the investment field is scarce.

In this article, we examine the effectiveness of a momentum strategy that takes into account ESG-criteria in the Russian stock market.

Momentum investment strategies are passive and based on the momentum effect on the stock market and other financial instruments. Momentum effect is a price anomaly when portfolios of stocks or other financial instruments, formed on the basis of the results of past activities, show excess returns to a given benchmark. Any indicators of investment efficiency (profitability of a financial instrument with or without risk) are used to assess the results of past activities. A market index or simulations based on generally accepted determinants of differences in asset returns (such as CAPM) can be used as a benchmark. The essence of momentum strategies is to form a portfolio of market "winners" (all who have shown, for example, a return above the average for the horizon, or only a share, for example, $10 \%$, of the considered sample of stocks) according to a specific performance indicator for a specific formation period, its rebalancing at a given frequency until the end of the portfolio holding period.

This article seeks to contribute to research on the effectiveness of the ESG-momentum strategy. The findings presented in this study are important for both retail and institutional investors.

\section{Materials and Methods}

\subsection{Literature Review}

After the global financial crisis, responsible investing researches have been intensified. The researchers examined the impact of environmental, social and governance factors on company performance and financial decisions on the Australian stock market [4].

ESG integration is conformed with a new generation of retail investors. More and more assets are being reallocated to Millennials and generation $\mathrm{Z}$, who prefer cleaner and healthier products and services. Retail investors are beginning to take a broader view of their investment decisions and assess their impact on society [5].

Responsible investing not only allows asset owners to consider their ethical preferences, offering a powerful potential for wealth creation, but also provides asset managers with the opportunity to reduce risk while improving the well-being of society.

ESG integration becomes the part of the fiduciary duty of institutional investors. The recognition and understanding of ESG-issues has a great importance for asset allocation. Demand from institutional investors is driving the growth of ESG integration [6].

The researchers analyzed the impact of including ESG as a separate factor in factor strategies on the American stock market [7]. Integrated ESG-factors provide higher Sharpe coefficients.

Investors focused on growth stocks and value stocks can integrate ESG-criteria forming their portfolios without lose of risk-adjusted returns [8]. When the ESG-rating of portfolio consisting of American and European stocks increases, the indicators of value and growth increase too.

In general, the results of research have shown that the integration of ESG into investment strategies doesn't have a negative impact on risk and profitability compared to investment strategies in which ESG is not integrated [9,10,11,12]. 
The momentum strategy, along with other factor strategies, is more effective during periods of market instability, slowing economic growth, and high inflation [13].

Today, a large number of empirical studies have concluded that momentum strategies provide statistically significant risk-adjusted returns on global stock markets over long periods of time $[14,15]$.

\subsection{Data and methodology}

Our paper test the following hypothesis: the level of momentum strategy effectiveness increases when responsible investing is applied.

We apply a non-ESG screening in order to create momentum strategy that deals with responsible investing (Momentum-ESG strategy). Firms that do not have ESG-score are removed when a non-ESG screening is applied. The remaining ESG-rated firms are sorted into "winners" and "losers" portfolios according their past returns. WML-ESG portfolio is created with buying "winners" and selling "losers".

Our study employ different time horizons of past returns for "winners" and "losers" formation (3, 6, 9 and 12 months of past returns excluding the last month due to a reversal effect [16]). "winners" and "losers" portfolio each contain 20\% (5 shares) of the MOEX RSPP Responsibility and Transparency Index (ESG-index). Investing period is from December 2011 to December 2020. The Portfolio composition is reviewed every month. All the portfolios are equal-weighted.

MOEX - RSPP Responsibility and Transparency Index is chosen as a source of the ESG-rated firms. This index includes 23 companies that meet high ESG-criteria and principles of responsible investment. These companies are checked according to 70 indicators that characterize responsible business practices (economic, environmental, social performance indicators and aspects of corporate governance).

Momentum-ESG strategy is compared with the simple momentum strategy. When simple momentum is applied, a set of companies (regardless their ESG-score) included in the MOEX Broad Market Index is taken under consideration. WML portfolio is created with buying "winners" and selling "losers". "winners" and "losers" portfolio each contain $20 \%$ (18 shares) of the MOEX Broad Market Index. Investing period is from December 2011 to December 2020. The Portfolio composition is reviewed every month. All the portfolios are equal-wheighted.

Comparing the Momentum-ESG strategy with the conventional Momentum strategy allows you assessing the impact of the ESG0-factor on investment performance. Transaction costs and taxes are not taken into account.

The algorithm for modeling the Momentum-ESG strategy involves the following stages:

1) an assessment of the profitability of shares included in the ESG-index for a specific time horizon;

2) the formation of a WML-ESG portfolio from long and short positions;

3) monthly rebalancing of the portfolio (if necessary) in accordance with the targets for its composition and structure. This implies a return to the first stage of the algorithm in case of deviation from target settings. The cycle (from stage 1 to stage 3 ) is repeated monthly until the end of the investing period;

4) at the end of the investing period, evaluation and comparison of the effectiveness of the Momentum-ESG strategy with the Momentum strategy.

A similar algorithm is used to form a WML portfolio (with a time horizon of 12, 9, 6 and 3 months) in the Momentum strategy, which does not imply screening by ESG-rating. 


\section{Results and Discussion}

Table 1 presents the effectiveness of Momentum-ESG strategies. These strategies vary in time horizons of past returns.

Table 1. The portfolios (Momentum-ESG strategy) effectiveness with different time horizons of past returns

\begin{tabular}{|l|c|c|c|c|}
\hline & \multicolumn{4}{|c|}{ Time horizons of past returns } \\
\cline { 2 - 5 } & $\mathbf{1 2}$ months & 9 months & 6 months & 3 months \\
\hline $\begin{array}{l}\text { Average monthly } \\
\text { return (\%) }\end{array}$ & 2.00 & 2.00 & 2.05 & 1.00 \\
\hline $\begin{array}{l}\text { Average monthly } \\
\text { volatility (\%) }\end{array}$ & 6.77 & 7.23 & 7.28 & 6.88 \\
\hline Sharpe ratio & $\mathbf{0 . 2 9 7}$ & 0.277 & 0.282 & 0.146 \\
\hline
\end{tabular}

When applying Momentum-ESG strategy and if the time horizon of past returns is 12 months, then WML-ESG portfolio shows the best results according to the Sharp ratio.

Fig. 1 presents the dynamics of the value of WML-ESG portfolios (with different time horizons of "winners" and "losers"). We measured the portfolios' value in conventional units and took these values as of December 12, 2011 as 1.

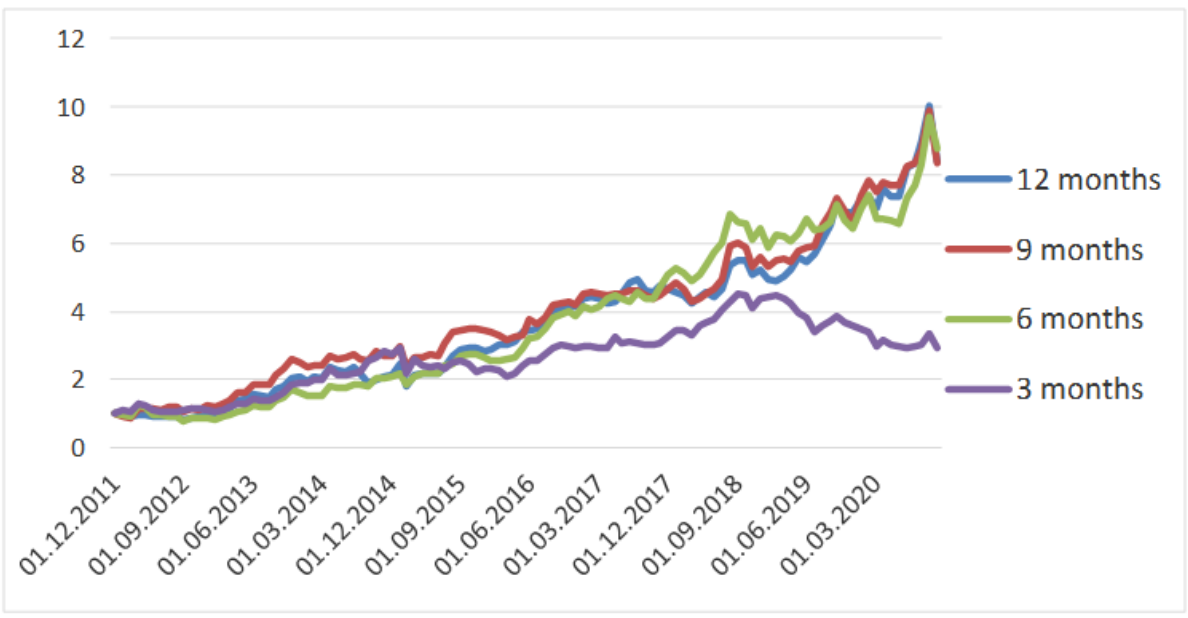

Fig. 1. Value of WML-ESG portfolios (Momentum-ESG strategy)

In order to compare Momentum-ESG and Momentum, effectiveness of the latter should be calculated as well. Table 2 introduces return and volatility measured for the set of WML portfolios which differs in time horizons of past returns.

Table 2. The portfolios (Momentum strategy) effectiveness with different time horizons of past returns

\begin{tabular}{|l|c|c|c|c|}
\hline & \multicolumn{4}{|c|}{ Time horizons of past returns } \\
\cline { 2 - 5 } & $\mathbf{1 2}$ months & 9 months & 6 months & 3 months \\
\hline $\begin{array}{l}\text { Average monthly } \\
\text { return (\%) }\end{array}$ & 1.07 & 0.97 & 0.96 & 0.80 \\
\hline $\begin{array}{l}\text { Average monthly } \\
\text { volatility (\%) }\end{array}$ & 5.72 & 5.40 & 4.94 & 4.799 \\
\hline Sharpe ratio & 0.188 & 0.179 & $\mathbf{0 . 1 9 4}$ & 0.168 \\
\hline
\end{tabular}

According to Table 2, the highest Sharpe ratio belongs to the 6 months WML portfolio. Fig. 2 presents the dynamics of the value of WML portfolios (with different time horizons 
of "winners" and "losers"). We measured the portfolios' value in conventional units and took these values as of December 12, 2011 as 1 .

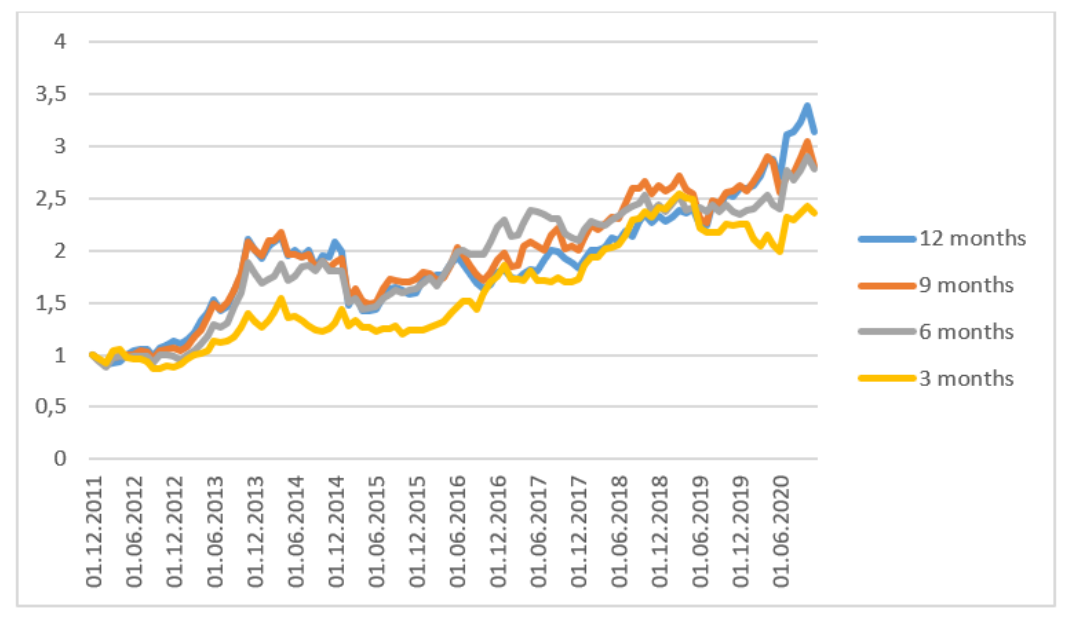

Fig. 2. Value of WML portfolios (Momentum strategy)

So, the final step is to compare momentum strategies using their best portfolios. Table 3 compares WML-ESG and WML portfolios using return and volatility measures.

Table 3. Effectiveness of WML-ESG and WML portfolios

\begin{tabular}{|l|c|c|c|}
\hline \multicolumn{1}{|c|}{$\begin{array}{c}\text { Portfolio and } \\
\text { strategy }\end{array}$} & $\begin{array}{c}\text { Average monthly } \\
\text { return (\%) }\end{array}$ & $\begin{array}{c}\text { Average monthly } \\
\text { volatility (\%) }\end{array}$ & Sharpe ratio \\
\hline $\begin{array}{l}\text { WML } \\
\text { (Momentum) }\end{array}$ & 0.96 & 4.94 & 0.194 \\
\hline $\begin{array}{l}\text { WML-ESG } \\
\text { (Momentum-ESG) }\end{array}$ & 2.00 & 6.77 & 0.297 \\
\hline
\end{tabular}

WML-ESG portfolio shows higher average monthly return. Despite of the WML-ESG portfolio's bigger volatility, its Sharpe ratio is 50\% larger compared to the WML portfolio's Sharpe ratio.

Fig. 3 presents the dynamics of the value of WML (6 months time horizon) and WMLESG portfolios (12 months time horizon). We measured the portfolios' value in conventional units and took these values as of December 12, 2011 as 1 .

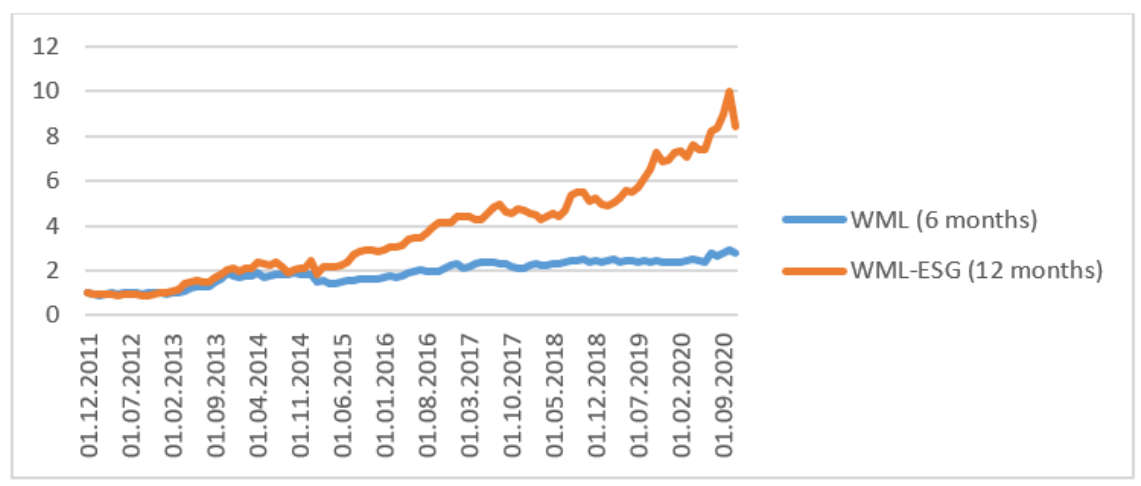

Fig 3. Value of WML and WML-ESG portfolios 
The value of WML-ESG portfolio is sustainably higher than the value of WML portfolio. Thus research confirmed the hypothesis about the positive impact of responsible investing on the effectiveness of momentum strategies in the conditions of the Russian stock market for the investing period.

\section{Conclusions}

Nowadays, responsible investments that are based on ESG-factors (environmental, social, corporate governance), are seen as a key element of sustainable development. That is why ESG criteria should be integrated into the investment business. However, the question of profitability of this integration process rises. Institutional investors, like any commercial organization, are profit-oriented. Studies conducted in developed stock markets shows the positive impact of considering ESG-factors in investment activities.

Our paper uses the Russian stock market (from December 2011 to December 2020) as a research setting. We aim to implement momentum strategies with Russian stocks. In order to integrate ESG-criteria into momentum strategy, a non-ESG is applied. It means that our Momentum-ESG strategy deals with ESG-firms only, while other firms are removed. MOEX - RSPP Responsibility and Transparency Index is chosen as a source of the ESGfirms. In other words, Momentum-ESG strategy is applied only to firms that are included in the MOEX - RSPP Responsibility and Transparency Index.

Momentum-ESG strategy is compared to the simple momentum strategy that is applied to firms that are included to the MOEX Broad Market Index. Results show that MomestumESG strategy is more effective than the simple momentum strategy. WML-ESG (10 shares) portfolio is less diversified compared to WML portfolio (36 shares). However, it shows much greater monthly average return.

Our results show that momentum strategy in integrating with responsible investing deserves attention from asset managers. This integration allows asset owners to take into account their ethical preferences with a high potential for increasing wealth and provides asset managers with the opportunity to improve investment performance.

Momentum strategies are very diverse. Our article shows a need for further research in the responsible and momentum investing direction.

The paper does not put an end to the study of the effectiveness of the integration of responsible investment into investment decision-making based on momentum strategies, but shows the need for further research in this direction.

\section{Acknowledgements}

The reported study was funded by RFBR, project number 20-310-90060.

\section{References}

1. N.P.B. Bollen, JFQA. 42, 683 (2007)

2. G. Gutsche, A. Ziegler, JBF, 102, 1155 (2019)

3. T.V. Teplova, FRM, 4, 282 (2013)

4. M. Limkriangkrai, S. Koh, R.B. Durand, IRF, 17, 461 (2017)

5. N.B. Boldyreva, L.G. Reshetnikova, E.A. Tarkhanova, Z.V. Pisarenko, S.A. Kalayda, JRFM, 13, 72 (2020) 
6. J.H. Fan, L. Michalski, IREF, 70, 230 (2020)

7. J. Bender, X. Sun, T. Wang, Thematic indexing, meet smart beta! merging ESG into factor portfolios (2017)

8. L. Kaiser, ESG integration: Value, growth and momentum (2018)

9. S. Brammer, C. Brooks, S. Pavelin, FM, 35, 97 (2006)

10. K. Cremers, V.B. Nair, JF, 60, 2859 (2005)

11. J.E. Humphrey, D.D. Lee, Y. Shen, AJM, 37, 135 (2012)

12. M. Statman, D. Glushkov, FAJ, 65, 33 (2009)

13. A. Ang, Asset management: A systematic approach to factor investing (2014)

14. N. Cakici, F.J. Fabozzi, S. Tan, Size, Value, and Momentum in Emerging Market Stock Returns (2012)

15. E.F. Fama, K.R. French, JFE, 105, 457 (2012)

16. E.S. Mikova, T.V. Teplova, FINIS, 41, 16 (2013) 